\title{
Correction to: SEOM clinical guideline of diagnosis and management of low-grade glioma (2017)
}

\author{
J. M. Sepúlveda-Sánchez ${ }^{1}$ • J. Muñoz Langa ${ }^{2} \cdot$ M. Á. Arráez ${ }^{3} \cdot$ J. Fuster $^{4} \cdot$ A. Hernández Laín ${ }^{5} \cdot$ G. Reynés ${ }^{2}$. \\ V. Rodríguez González ${ }^{6} \cdot$ E. Vicente $^{7} \cdot M$. Vidal Denis ${ }^{8} \cdot$ Ó. Gallego $^{9}$
}

Published online: 5 December 2017

(c) Federación de Sociedades Españolas de Oncología (FESEO) 2017

\section{Correction to: Clin Transl Oncol https://doi.org/10.1007/s12094-017-1790-3}

The original version of this article unfortunately contained a mistake. Figure 3 was incorrect. The correct Fig. 3 is given below:

The original article can be found online at https://doi. org/10.1007/s12094-017-1790-3.

\section{J. M. Sepúlveda-Sánchez} juanmanuel.sepulveda@salud.madrid.org

1 Neurooncology Unit, Hospital Universitario, 12 de Octubre, Madrid, Spain

2 Medical Oncology Department, Hospital Universitari I Politècnic la Fe, Valencia, Spain

3 Neurosurgery Department, HRU Carlos Haya, Málaga, Spain

4 Medical Oncology Department, Hospital Universitari Son Espases, Palma de Mallorca, Spain

5 Neuropathology Department, Hospital Universitario, 12 de Octubre, Madrid, Spain

6 Radiation Oncology Department, Hospital Universitario, 12 de Octubre, Madrid, Spain

7 Medical Oncology Department, C.H.U. Insular-Materno Infantil de Gran Canaria, Las Palmas, Spain

8 Neuroradiology Unit, HRU Carlos Haya, Málaga, Spain

9 Medical Oncology Department, Hospital de la Santa Creu I Sant Pau, Barcelona, Spain 
Fig. 3 Therapeutic algorithm for diffuse low-grade gliomas

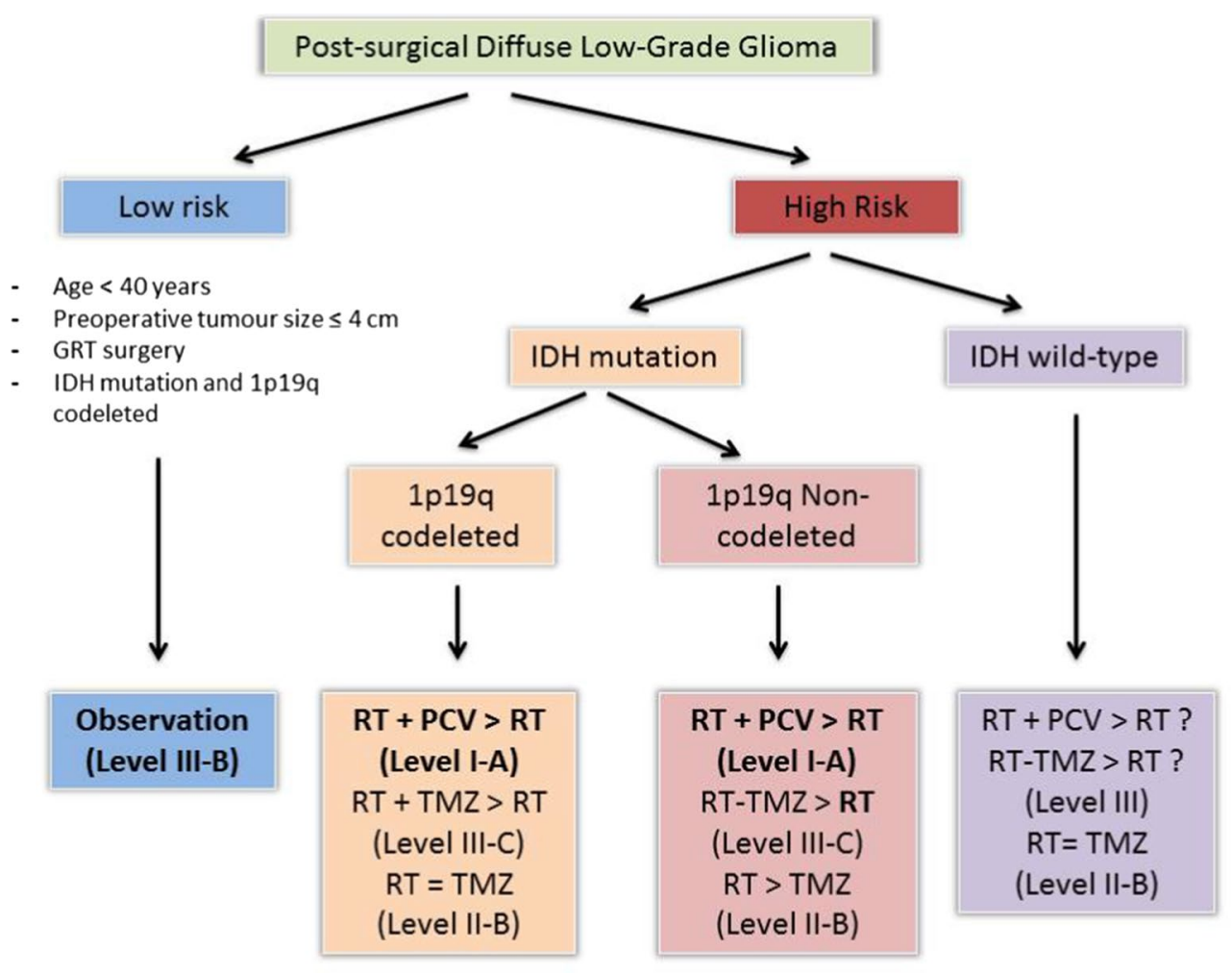

